\title{
Best Possible Medication History in the Emergency Department: Comparing Pharmacy Technicians and Pharmacists
}

\author{
Rochelle Johnston, Lauza Saulnier, and Odette Gould
}

\begin{abstract}
Background: Obtaining an accurate and complete medication list (i.e., the best possible medication history $[\mathrm{BPMH}]$ ) is the first step in completing medication reconciliation. The ability of pharmacy technicians to obtain medication histories, relative to that of pharmacists, has not been formally assessed.
\end{abstract}

Objectives: To determine whether pharmacy technicians at the authors institution could obtain a BPMH as accurately and completely as pharmacists and if both groups met national norms for unintentional discrepancies and the success index for medication reconciliation.

Methods: Pharmacy technicians were trained in obtaining a BPMH at the beginning of the study, before any patients were enrolled. Patients presenting to the emergency department were prospectively enrolled to be interviewed separately by both a pharmacist and a technician, with information recorded on standard medication reconciliation forms. The completed forms for each patient were compared following each set of interviews, and discrepancies were clarified with the patient.

Results: Fifty-nine patients were included in the study, and 3 pharmacists and 2 technicians obtained the histories. There was no significant difference between pharmacists and technicians in terms of discrepancies involving prescription drugs $\left(\chi^{2}=0.52, \mathrm{df}=1, n=118, p=0.47\right.$, Cramer's $V$ for effect size $=0.07)$ or over-the-counter medications $\left(\chi^{2}=\right.$ $0.09, \mathrm{df}=1, n=118, p=0.77$, Cramer's $V=0.03$ ). The mean number of discrepancies per patient did not differ significantly between the pharmacists and technicians $(t=0.15, \mathrm{df}=58, p=0.88$ for prescription drugs; $t=-0.22, \mathrm{df}=58, p=0.83$ for over-the-counter products). For both groups, the number of unintentional discrepancies per patient was significantly lower and the success index for medication reconciliation significantly higher than the national average.

Conclusions: Trained pharmacy technicians at the authors' institution were able to obtain a BPMH with as much accuracy and completeness as pharmacists. Both groups were significantly superior to the national average in terms of unintentional discrepancies and success index for medication reconciliation.

Key words: medication reconciliation, pharmacy technician, best possible medication history, BPMH, emergency department

Can J Hosp Pharm 2010;63(5):359-365

\section{RÉSUMÉ}

Contexte : Lobtention d'une liste précise et complète des médicaments (c.-à-d. le meilleur schéma thérapeutique possible [MSTP]) est la première étape du bilan comparatif des médicaments. La capacité des techniciens en pharmacie, comparativement à celle des pharmaciens, d'obtenir les histoires médicamenteuses n’a pas été évaluée officiellement.

Objectifs : Déterminer si les techniciens en pharmacie dans l'établissement des auteurs pouvaient obtenir un MSTP aussi précis et complet que les pharmaciens et si les deux groupes satisfaisaient aux normes nationales pour ce qui est des divergences non intentionnelles et de l'indice de réussite pour ce qui est du bilan comparatif des médicaments.

Méthodes : Les techniciens en pharmacie ont été formés sur la technique d'obtention du MSTP au début de l'étude, avant l'inscription des patients. Les patients qui consultaient au service des urgences ont été inscrits de façon prospective pour être interviewés séparément par un pharmacien et par un technicien, et l'information était consignée sur des formulaires standard de bilan comparatif des médicaments. Les formulaires remplis pour chaque patient ont été comparés à la suite de chaque série d'entrevues, et les divergences ont été clarifiées avec les patients.

Résultats : Un total de 59 patients ont été inscrits à l'étude. Trois pharmaciens et deux techniciens ont obtenu les histoires médicamenteuses. Aucune différence significative n'a été observée entre les pharmaciens et les techniciens pour ce qui est des divergences au chapitre des médicaments d'ordonnance $(\chi 2=0,52, \mathrm{df}=1, n=118, p=0,47, V$ de Cramer pour l'ampleur de l'effet $=0,07)$ ou des médicaments en vente libre $\left(\chi^{2}\right.$ $=0,09, \mathrm{df}=1, n=118, p=0,77, \mathrm{~V}$ de Cramer $=0,03)$. Aucune différence significative n'a été observée quant au nombre moyen de divergences par patient entre les pharmaciens et les techniciens $(t=0,15, \mathrm{df}=58, p=0,88$ pour les médicaments d'ordonnance; $t=-0,22, \mathrm{df}=58, p=0,83$ pour les produits en vente libre). Le nombre de divergences non intentionnelles par patient pour les deux groupes était significativement plus bas et l'indice de réussite pour ce qui est du bilan comparatif des médicaments était significativement plus élevé que les moyennes nationales.

Conclusions : Les techniciens en pharmacie qualifiés dans l'établissement des auteurs ont pu obtenir un MSTP aussi précis et complet que celui des pharmaciens. Les deux groupes ont eu des résultats significativement supérieurs à ceux de la moyenne nationale quant aux divergences non intentionnelles et à l'indice de réussite pour ce qui est du bilan comparatif des médicaments.

Mots clés : bilan comparatif des médicaments, technicien en pharmacie, meilleur schéma thérapeutique possible, MSTP, service des urgences

[Traduction par l'éditeur] 


\section{INTRODUCTION}

$\mathrm{M}$ edication reconciliation is a formal process of obtaining a complete and accurate list of each patient's current home medications and comparing the list with orders written at each transition of care. The Safer Healthcare Now! Campaign is a national program intended to improve the safety of the Canadian health care system. The campaign consists of a variety of initiatives, one of which is preventing adverse drug events by means of medication reconciliation. ${ }^{1}$

The most intricate part of medication reconciliation is obtaining the best possible medication history (BPMH). The $\mathrm{BPMH}$ is a comprehensive, systematically derived list of regularly used medications, both prescription and nonprescription agents. Obtaining an accurate and complete medication history is crucial, as it forms the basis of medication reconciliation from admission through to discharge. ${ }^{2}$ Incomplete or inaccurate medication histories can increase the risk of medication-related errors and complications. ${ }^{3}$

The process of obtaining a patient's BPMH can be initiated by any member of the health care team. Pharmacists have extensive training in obtaining medication histories, and it has been proven that BPMHs obtained by pharmacists are more accurate and more complete than those obtained by other health care professionals. In an emergency department setting, Carter and others ${ }^{4}$ compared medication histories obtained by clinical pharmacists with those obtained by other health care providers, including physicians, nurses, and medical students. Although no statistical analyses were carried out, the researchers found that the pharmacists identified 279 additional home medications among 252 patients relative to the other health care providers (1096 versus 817 medications). Reeder and Mutnick $^{3}$ conducted a similar study comparing medication histories obtained by physicians and pharmacists for patients admitted to an internal medicine service and concluded that the medication histories obtained by pharmacists were significantly more complete. Pharmacists identified 58 more medications than physicians; they also identified 353 discrepancies in 55 patients.

Although research to date has shown that pharmacists obtain the most accurate and comprehensive BPMHs, pharmacist shortages and time constraints may make it impractical to routinely assign this duty to this group of health care professionals. ${ }^{5}$ As such, new practice models must be considered to ensure that accurate and complete medication histories are obtained by properly trained members of the health care team. One group of individuals that might be considered for this role is pharmacy technicians. Several studies have investigated the involvement of pharmacy technicians in medication reconciliation, all with positive results..$^{5-8}$ In one study, Michels and others ${ }^{5}$ found that utilization of well-trained pharmacy technicians to obtain medication histories before scheduled surgical admissions reduced potential adverse drug events by more than $80 \%$ within 3 months of implementation, relative to the 6 weeks before involvement of technicians. Another study, performed in a preoperative clinic in the Netherlands, compared the number of medication discrepancies before and after implementation of medication reconciliation by pharmacy technicians. ${ }^{6}$ The number of patients with medication discrepancies decreased significantly (by $13.2 \%$ ) following assignment of technicians to this task.

At The Moncton Hospital, medication reconciliation at the time of admission has been performed by pharmacists, nurses, and physicians for more than 12 years. Pharmacy technicians are teamed with pharmacists in multiple direct patient care areas, including the emergency department. Pharmacist coverage in the emergency department is from 0830 to 2030, Monday to Thursday, and from 0830 to 1630 on Friday; technician coverage is from 0800 to 1500 , Monday to Friday. On average, $16 \mathrm{BPMHs}$ are obtained daily by pharmacists in the emergency department. One duty undertaken by pharmacy technicians working in the emergency department is to obtain a preliminary medication list before the pharmacist completes the BPMH. The technician reviews the patient's medication vials and medication profile and contacts community pharmacies if necessary for clarification of prescriptions. The pharmacist uses the information obtained by the technician to complete the $\mathrm{BPMH}$, and this record is then used by the physician to write the admission medication orders.

The primary objectives of this study were to prospectively determine whether pharmacy technicians could obtain a $\mathrm{BPMH}$ in the emergency department with accuracy and completeness similar to that of pharmacists, and to determine if the pharmacists and pharmacy technicians at the authors' institution met the national norms for unintentional discrepancies and the success index for medication reconciliation, as reported by Safer Healthcare Now! A secondary objective was to determine the average length of time for technicians and pharmacists to obtain a BPMH.

\section{METHODS}

This study was a prospective comparison of current medication histories obtained by pharmacy technicians and by pharmacists in the emergency department at The Moncton Hospital, a 400-bed community hospital. The emergency department at this institution is a combined adult and pediatric care facility that is designated as a level II trauma centre, with about 55000 visits annually. During December 2008, patients presenting to the emergency department were enrolled to be interviewed 2 times, once by a pharmacist and once by a technician. Patient recruitment took place on weekdays during daytime hours (0830 to 1700). Patients were eligible for inclusion 
if they were being admitted to hospital from the emergency department or if a member of the health care team asked a pharmacist for a medication history. Patients were excluded if they had been transferred from a nursing home or other hospital or if a medication history had been initiated by a health care professional other than a pharmacist. Three pharmacists and 2 technicians participated in the study.

The pharmacy technicians were trained to obtain a BPMH by means of a 4-step process adapted from the medication reconciliation education and certification program described by Small and others. ${ }^{9}$ First, an interactive learning and education session was provided, during which background information was reviewed and tips for success when obtaining a BPMH were outlined. During this session, the technicians were given a $\mathrm{BPMH}$ interview guide, adapted with permission from an existing interview guide,$^{10}$ which outlined appropriate probing questions. The technicians were expected to use this guide for each interview that they completed. A similar tool can be obtained from www.SaferHealthcareNow.ca. Second, required background readings were supplied, to be completed before initiation of the study. Third, each technician participated in several practice interviews, during which he or she interviewed a patient after a pharmacist had done so; the histories obtained by pharmacist and technician were compared, and discrepancies were reviewed and discussed. Finally, each technician underwent a competency assessment, during which he or she interviewed a standardized patient and received detailed feedback from the assessor. This training program and related tools were also offered to the 3 pharmacists assigned to the emergency department.

Patients who met the inclusion criteria were randomly assigned, by means of sealed-envelope randomization, to participate or not participate in the study. As per usual practice, the technicians used multiple resources (e.g., medication list, prescription vials, community pharmacy profile) to prepare a preliminary medication list for patients. For patients assigned to not participate, this list was given to the pharmacist only, and no further data were collected for the study. For patients assigned to participate, this list was given to both the technician and the pharmacist for subsequent interviews with the patient. For each patient, the technician who prepared the preliminary list also conducted the interview. Because this procedure replicated those used for medication reconciliation audits in the Safer Healthcare Now! Campaign at the authors' institution, patient consent was implied, and patients were simply informed that they would be interviewed twice as part of the study. A second sealed-envelope randomization was performed to determine the order of interviews by technician and pharmacist: half of the patients in the study were interviewed by the pharmacist first and the technician second, and the other half were interviewed by the technician first and the pharmacist second. The interviewers recorded the approximate start and stop times of the patient interviews on study log sheets. The randomized order of the interviews served as an experimental control, and all comparisons between pharmacists and technicians were carried out by contrasting data from interviews with the same patients (i.e., within-subject analysis).

After each set of interviews, the principal investigator (R.J.) reviewed both histories within 24 h. Each history was compared to the final $\mathrm{BPMH}$, as determined by the principal investigator on the basis of a review of the patient's prescription medication vials and community pharmacy medication profile, a call to the community pharmacist (if necessary), and the combined results of the interviews carried out by the pharmacist and the technician. If the principal investigator found any discrepancies between a patient's medication list as prepared by the pharmacist or the technician and the final $\mathrm{BPMH}$, she clarified the issue with the patient. Patients who were no longer in the hospital were contacted at home. The following discrepancies were coded: omission of a prescription drug, omission of an over-the-counter drug, incorrect drug (prescription or over-the-counter), discrepant dose or frequency (for prescription or over-the-counter drug).

After the study was complete, 3 pharmacists who had not been involved with the study independently classified each discrepancy for its potential severity, according to the classification system of Cornish and others ${ }^{11}$ : a class 1 discrepancy was defined as unlikely to cause discomfort to the patient or clinical deterioration, a class 2 discrepancy had the potential to cause moderate discomfort or clinical deterioration, and a class 3 discrepancy had the potential to result in severe discomfort or clinical deterioration. Disagreements were resolved by group discussion, and consensus was reached for all discrepancies.

Descriptive and statistical analyses were completed with SPSS version 16.0 (SPSS Inc, Chicago, Illinois). Descriptive statistics were used to describe the sample in terms of age and numbers of prescription and over-the-counter medications and to describe the length of the interviews. Pearson correlations were performed to analyze relationships between discrepancies and variables of interest (e.g., age of patient, number of medications). Spearman correlations were also calculated for all relationships.

Exploratory analyses were performed using dependent group $\chi^{2}$ tests and $t$ tests. The data for pharmacists and technicians in this study were compared with national norms data for December 2008 (obtained from the March 2009 Safer Healthcare Now! quarterly report) using a series of 1 -sample $t$ tests for per-patient unintentional discrepancies and success index. For all $\chi^{2}$ tests, effect size is reported using Cramer's $V$. For all $t$ tests, effect size is reported using eta squared $\left(\eta^{2}\right)$. The values for Cramer's $V$ and $\eta^{2}$ represent the proportion of the variance in the dependent variable accounted for by the independent 
variable. For Cramer's $V$, values of 0.10 to 0.20 are considered weak, values of 0.20 to 0.30 are considered midrange, and values above 0.30 are considered large. For $\eta^{2}$, values in the range of 0.01 are usually considered small, values close to 0.06 are considered midrange, and values in the range of 0.14 are usually considered large.

The Horizon Health Network Research Ethics Board approved the protocol for this study.

\section{RESULTS}

Of 120 patients identified during December 2008 as being eligible for inclusion, 60 were enrolled and 60 were assigned to not participate. Thirty of the enrolled patients were interviewed first by the pharmacist, and 30 patients were interviewed first by the technician. One of the patients interviewed was excluded from the analysis because both the patient and the patient's spouse had severe cognitive dysfunction and confusion and were unable to provide the necessary information. For other patients who were either unable to communicate or who had cognitive dysfunction, information was gathered from caregivers or family members. A total of 59 patients were included in the final analysis (Table 1).

On the basis of interviews conducted with the 59 patients, the pharmacists had no unintentional discrepancies for prescription medications for 47 patients, and the technicians had no unintentional discrepancies of this type for 50 patients. The difference between the 2 groups was not statistically significant $(p=0.47)$ (Table 2). Similarly, the mean number of discrepancies per patient for prescription medications did not differ significantly between pharmacists and technicians $(0.25$ versus $0.24 ; p=0.88)$.

Table 1. Characteristics of 59 Participants in a Study of Medication Reconciliation in the Emergency Department

Characteristic

Sex

Male

Female

Age (years)

Mean (SD)

Range

Time of enrolment

0800 to 1059

1100 to 1359

1400 to 1700

No. of medications per patient

Prescription

Mean (SD)

Range

Over-the-counter or herbal products

Mean (SD)

Range

SD = standard deviation

The pharmacists had no unintentional discrepancies for over-the-counter medications for 52 patients, and the technicians had no unintentional discrepancies of this type for 53 patients. This difference was not statistically significant $(p=0.77)$ (Table 2). The mean numbers of discrepancies per patient for over-the-counter medications did not differ significantly between pharmacists and technicians ( 0.14 versus $0.15 ; p=0.83$ ) (Table 2).

There was no significant difference in the mean number of discrepancies between the first and second interviews $(t=-0.31$,

Table 2. Discrepancies for Prescription and Over-the-Counter Drugs

\begin{tabular}{|c|c|c|c|c|}
\hline \multirow[b]{2}{*}{ Product Type } & \multicolumn{2}{|c|}{ No. of Patients with Discrepancies* } & \multirow[b]{2}{*}{ Statistic } & \multirow[b]{2}{*}{$p$ value } \\
\hline & $\begin{array}{c}\text { Pharmacist } \\
\text { Performing } \\
\text { Reconciliation }\end{array}$ & $\begin{array}{c}\text { Technician } \\
\text { Performing } \\
\text { Reconciliation }\end{array}$ & & \\
\hline Prescription drugs & & & $\begin{array}{c}\chi^{2}=0.52, d f=1 \\
(n=118)\end{array}$ & $\begin{array}{c}0.47 \\
(\text { Cramer's } V=0.07)\end{array}$ \\
\hline No discrepancies & 47 & 50 & & \\
\hline At least 1 discrepancy & 12 & 9 & & \\
\hline Over-the-counter products & & & $\begin{array}{c}\chi^{2}=0.09, d f=1 \\
(n=118)\end{array}$ & $\begin{array}{c}0.77 \\
\text { (Cramer's V }=0.03)\end{array}$ \\
\hline No discrepancies & 52 & 53 & & \\
\hline At least 1 discrepancy & 7 & 6 & & \\
\hline \multicolumn{5}{|l|}{$\begin{array}{l}\text { Discrepancies per patient } \\
\text { (mean } \pm \text { SD) }\end{array}$} \\
\hline Prescription drugs & $0.25 \pm 0.54$ & $0.24 \pm 0.68$ & $t=0.15, \mathrm{df}=58$ & $\begin{array}{c}0.88 \\
\left(\eta^{2}<0.001\right)\end{array}$ \\
\hline Over-the-counter products & $0.14 \pm 0.39$ & $0.15 \pm 0.48$ & $t=-0.22, \mathrm{df}=58$ & $\begin{array}{c}0.83 \\
\left(\eta^{2}=0.001\right)\end{array}$ \\
\hline
\end{tabular}

$\mathrm{SD}=$ standard deviation .

*Except where indicated otherwise. 
df $\left.=58, p=0.76, \eta^{2}<0.002\right)$. Similarly, there were no statistically significant differences among the 3 pharmacists or between the 2 technicians in terms of discrepancies for prescription or over-the-counter medications.

The principal investigator identified various types of discrepancies, with various levels of severity, in the BPMHs prepared by pharmacists and technicians (Table 3). Evaluation of the BPMHs prepared by pharmacists revealed 12 class 1 discrepancies, 9 class 2 discrepancies, and 2 class 3 discrepancies (23 discrepancies total). The discrepancies with class 3 severity are summarized in Table 4. Review of the BPMHs prepared by technicians revealed 17 class 1 discrepancies, 6 class 2 discrepancies, and no class 3 discrepancies (23 total discrepancies). A weighted sum of errors was calculated for each patient, whereby each error was multiplied by its severity score, and values were summed for each patient. The mean weighted severity sum per patient for prescription medications did not differ significantly: 0.42 (standard deviation [SD] 0.95) for pharmacists and 0.34 (SD 0.94) for technicians $(t=0.50$, $\left.\mathrm{df}=58, p=0.62, \eta^{2}=0.004\right)$. Similarly, the mean weighted severity sum per patient for over-the-counter medications did not differ significantly: 0.17 (SD 0.50) for pharmacists and 0.14 (SD 0.70) for technicians $(t=0.39, \mathrm{df}=58, p=0.70$, $\left.\eta^{2}=0.003\right)$.

An unintentional discrepancy is defined by Safer Healthcare Now! as a medication error that can lead to one or more adverse drug events. ${ }^{1}$ The national average for unintentional discrepancies per patient for December 2008 was 0.54 , as reported in the March 2009 quarterly report for medication reconciliation. In the current study, the pharmacists had a mean of 0.25 (SD $0.54)$ unintentional discrepancies per patient, and the technicians had a mean of 0.24 (SD 0.68) unintentional discrepancies per patient. For both groups, the value was significantly lower than the national average for unintentional discrepancies per Table 3. Type and Potential Severity of Discrepancies* in Best Possible Medication Histories
(BPMHs) Prepared by Pharmacists and Pharmacy Technicians

\begin{tabular}{|c|c|c|c|}
\hline Type of Discrepancy & Class 1 & Class 2 & Class 3 \\
\hline \multicolumn{4}{|l|}{ Omission of prescription medication } \\
\hline In BPMHs prepared by pharmacists ( 6 patients) & 2 & 5 & 0 \\
\hline In BPMHs prepared by technicians ( 4 patients) & 3 & 1 & 0 \\
\hline \multicolumn{4}{|l|}{ Omission of over-the-counter or herbal product } \\
\hline In BPMHs prepared by pharmacists (6 patients) & 6 & 1 & 0 \\
\hline In BPMHs prepared by technicians (5 patients) & 7 & 0 & 0 \\
\hline \multicolumn{4}{|c|}{ Incorrect drug (prescription or over-the-counter) } \\
\hline In BPMHs prepared by pharmacists (1 patient) & 0 & 0 & 1 \\
\hline In BPMHs prepared by technicians (1 patient) & 1 & 0 & 0 \\
\hline \multicolumn{4}{|c|}{ Discrepant dose (prescription or over-the-counter) } \\
\hline In BPMHs prepared by pharmacists (3 patients) & 1 & 1 & 1 \\
\hline In BPMHs prepared by technicians ( 2 patients) & 1 & 1 & 0 \\
\hline \multicolumn{4}{|l|}{$\begin{array}{l}\text { Discrepant frequency } \\
\text { (prescription or over-the-counter) }\end{array}$} \\
\hline In BPMHs prepared by pharmacists (5 patients) & 3 & 2 & 0 \\
\hline IIn BPMHs prepared by technicians (8 patients) & 5 & 4 & 0 \\
\hline
\end{tabular}

${ }^{*}$ Class 1 = unlikely to cause discomfort or deterioration, class 2 = potential to cause discomfort or deterioration, class $3=$ potential to cause severe discomfort or deterioration.

Table 4. Descriptions of Discrepancies with Class 3 Severity

Patient Data

77-year-old woman presenting to emergency department with dysuria
Medications

Allopurinol, ASA, bisoprolol, domperidone, furosemide, insulin, isosorbide dinitrate, lansoprazole nifedipine $\mathrm{XL}$, paroxetine, rosuvastatin, valsartan, warfarin

58-year-old man presenting to emergency department with chest pain
Hydrochlorothiazide, ibuprofen, nifedipine $\mathrm{XL}$, propranolol LA

\section{Discrepancy}

Bisoprolol:

Blister package label read and transcribed by pharmacist as "bisoprolol 5 mg 11/2 tabs daily" Actual dosage as written on blister package label: bisoprolol $5 \mathrm{mg}$ $1 / 2$ tab daily

Atenolol :

Documented by pharmacist as a home medication

Drug had been discontinued before admission and replaced with propranolol 
patient (for pharmacists, $t=-4.03$, df $=58, p<0.001, \eta^{2}=$ 0.22 ; for technicians, $t=-3.43, \mathrm{df}=58, p=0.001, \eta^{2}=0.17$ ).

The success index refers to the total percentage of correct or acceptable orders recorded in a list of medications prepared for the purposes of medication reconciliation. ${ }^{1}$ For December 2008 , the national average for the success index was $87.48 \%$, as reported in the Safer Healthcare Now! March 2009 quarterly report. In the current study, the mean success index was 95.48\% (SD 11.72\%) for pharmacists and 97.05\% (SD $7.47 \%$ ) for technicians. For both groups, the value was significantly higher than the national average: for pharmacists, $t=5.02, \mathrm{df}=53, p<0.001, \eta^{2}=0.32$; for technicians, $t=9.08$, df $=53, p<0.001, \eta^{2}=0.61$.

On average, the interviews by pharmacists took $9.24 \mathrm{~min}$ (SD $4.75 \mathrm{~min}$ ) to complete, and those by technicians took 7.96 $\min (\mathrm{SD} 4.60)$. The interviews by technicians were significantly shorter than those by pharmacists $(t=3.24$, df $=54$, $\left.p=0.002, \eta^{2}<0.16\right)$. These times captured the interviews only, not preparation of the preliminary medication list.

Pearson correlations showed that older patients were more likely than younger patients to be taking many prescription medications $(r=0.41, n=59, p=0.001)$ and were more likely to have longer interviews with both the pharmacists $(r=0.45$, $n=55, p<0.001)$ and the technicians $(r=0.47, n=55$, $p<0.001)$. A higher number of prescription medications was correlated with more discrepancies for prescription medications in BPMHs prepared by technicians ( $r=0.32, n=59, p=0.01$ ), but this correlation was not statistically significant for the pharmacists $(r=0.22, n=59, p=0.09)$. The relationship between discrepancies for prescription medications and time of enrolment in the study was not statistically significant for either group $(r=-0.25, n=59, p=0.05$ for interviews conducted by pharmacists; $r=0.02, n=59, p=0.86$ for interviews conducted by technicians).

\section{DISCUSSION}

To the authors' knowledge, this study is the first randomized trial directly comparing medication histories obtained by pharmacists with those obtained by pharmacy technicians. Previous studies have examined medication reconciliation and the role of the pharmacy technician in both preoperative and hemodialysis clinics and have obtained favourable results. ${ }^{5-7}$ However, the role of the pharmacy technician in the emergency department, although increasing in popularity, is not as well studied. The results obtained here confirm the hypothesis that in the emergency department, well-trained pharmacy technicians can obtain a BPMH with as much accuracy and completeness as pharmacists.

The process of medication reconciliation is a responsibility shared among the members of the health care team. Using the best skill mix for this task is of great importance, and it is vital to take advantage of the knowledge, skills, and abilities of all groups involved to properly allocate and utilize resources. That being said, the results reported here have the potential to benefit various members of the health care team who are involved in performing medication reconciliation. The involvement of pharmacy technicians in innovative and nontraditional roles can ultimately improve their job satisfaction and aid in retention of staff. Delegation of this task allows for enhanced facilitation of the pharmacist's responsibilities, which can ultimately increase the time available to the pharmacist for providing more in-depth clinical services and resolving drug therapy problems. This, in turn, will increase pharmacists' job satisfaction and facilitate human resources management through improved recruitment and retention of staff. With additional team members involved in the medication reconciliation process, it should be possible to provide this service more consistently, which will contribute to improved patient safety through avoidance of adverse drug events.

One notable finding was the difference in duration of interviews conducted by pharmacists and technicians. Although the total time recorded for each interview was approximate, interviews conducted by technicians were significantly shorter than those completed by pharmacists (7.96 versus $9.24 \mathrm{~min}$ ). This difference might be explained by the fact that pharmacists often spend time inquiring about clinical issues. At least 2 other studies have examined the time taken by pharmacy technicians to complete a BPMH, reporting an average of $17 \mathrm{~min}$ for hemodialysis patients ${ }^{7}$ and an average of 12 min for medical patients. ${ }^{8}$ If the BPMH obtained by a technician is accurate and complete, as shown by the results reported here, more time is freed up for the pharmacist to assess and resolve clinical medication-related problems. In addition, although we anticipated that it might take the technicians longer to complete their interviews with patients, we have shown that the benefit of a technician's assistance can be achieved without any requirement for additional time.

We believe that all staff involved in medication reconciliation could benefit from a training program similar to that used to train the technicians in this study. A systematic approach to obtaining the BPMH is essential to the success of medication reconciliation. Leung and others ${ }^{7}$ used a 2 -week period to train technicians in a hemodialysis clinic to obtain a BPMH. The training consisted of interview training, observation, and practice under the direct supervision of a pharmacist. During the assessment phase of their study, these authors found that pharmacists agreed on $98.1 \%$ of the orders identified by technicians during their interviews with 99 patients, and they concluded that an adequately trained technician was capable of interviewing patients to create a BPMH. In another study at the same institution, a similar 7-day training program was used, and the authors identified 775 discrepancies among 326 
medical patients from interviews conducted by pharmacy technicians. ${ }^{8}$ Small and others ${ }^{9}$ pilot-tested a structured admission medication reconciliation education and certification program for hospital pharmacists. Although they did not perform any statistical analyses, these authors concluded that participants who used a "trigger sheet", such as that used in our study, had higher accuracy scores in the certification phase than those who did not (88.1\% versus $67.1 \%)$. The training and certification program used in our study was a modified version of that used by Small and others. ${ }^{9}$ It will be used in our institution for future training of pharmacy staff members.

The limitations of this study included the small sample size (59 patients) and the short duration (data collection over 1 month). In addition, the principal investigator was not blinded. Conversely, all data were reported by means of standard forms that required complete information, which we believe limited the amount of bias introduced. In addition, for each patient, the technician who completed the research to create the preliminary medication list also interviewed the patient. Although this might have created bias in favour of the technician, both the technician and the pharmacist began their interviews with the same information available to them. Moreover, this procedure mimics what actually happens in the emergency department, where the technicians routinely carry out the research to establish the preliminary medication list. Another notable limitation was the daily timeframe of the study: only patients who presented to the emergency department during daytime hours were included, whereas Safer Healthcare Now! audits typically include multiple hospital units and are not limited to daytime shifts.

One strength of this study was the inclusiveness of the sample. Only patients from nursing homes or other hospitals (i.e., patients who had medication administration records) and patients whose medication history had been obtained by a physician or nurse were excluded. As such, the screening process carried out by the technician was based on completely objective criteria.

These results may not be generalizable to all hospital sites. At the authors' institution, pharmacy technicians have been working in direct patient care areas, such as the emergency department, for several years. This has given them experience and comfort in participating in the multidisciplinary team and communicating with patients. At sites where pharmacy technicians fulfill strictly traditional roles, the technicians will probably require further training and experience before the results obtained in this study can be duplicated.

\section{CONCLUSIONS}

There were no statistically significant differences between pharmacists and trained pharmacy technicians in terms of the presence of discrepancies for prescription or over-the-counter drugs or the mean number of discrepancies for each type of medication. Furthermore, the severity of discrepancies was not significantly different between the 2 groups. Both pharmacists and technicians at this institution were significantly superior to the national average for unintentional discrepancies and success index, as reported in the March 2009 Safer Healthcare Now! quarterly report (for December 2008).

\section{References}

1. Safer Healthcare Now! Getting started kit: medication reconciliation prevention of adverse drug events: how-to guide. Edmonton (AB): Canadian Patient Safety Institute; 2007 [cited 2007 May]. Available from: www.saferhealthcarenow.ca/EN/Interventions/medrec_acute/ Documents/Med\%20Rec\%20(Acute\%20Care)\%20Getting\% 20Started\%20Kit.pdf

2. Fernandes O. Practical strategies for medication reconciliation: changing how we do business from admission to discharge [presentation]. Medication Reconciliation Workshop; 2007 Jun; London (ON).

3. Reeder TA, Mutnick A. Pharmacist- versus physician-obtained medication histories. Am J Health Syst Pharm 2008;65(9):857-860.

4. Carter MK, Allin DM, Scott LA, Grauer D. Pharmacist-acquired medication histories in a university hospital emergency department. Am J Health Syst Pharm 2006;63(24):2500-2503.

5. Michels RD, Meisel SB. Program using pharmacy technicians to obtain medication histories. Am J Health Syst Pharm 2003;60(19):1982-1986.

6. van den Bemt PM, van den Broek S, van Nunen AK, Harbers JB, Lenderink AW. Medication reconciliation performed by pharmacy technicians at the time of preoperative screening. Ann Pharmacother 2009;43(5):868-874.

7. Leung M, Jung J, Lau W, Kiaii M, Jung B. Best possible medication history for hemodialysis patients obtained by a pharmacy technician. Can J Hosp Pharm 2009;62(5):386-391.

8. Remtulla S, Brown G, Frighetto L. Best possible medication history by a pharmacy technician at a tertiary care hospital. Can J Hosp Pharm 2009;62(5):402-405.

9. Small K, Fernandes O, Wong J, Wong M, Huh J, Musing E, Bajcar J. Development and implementation of an admission medication reconciliation education and certification program for pharmacists [abstract]. Can J Hosp Pharm 2007;60 Suppl 1:63.

10. Chhibbar S, Ingram S, Fernandes O, Watt A. Best possible medication history interview guide. Toronto $(\mathrm{ON})$ : Institute for Safe Medication Practices Canada; 2008.

11. Cornish PL, Knowles SR, Marchesano R, Tam V, Shadowitz S, Juurlink $\mathrm{DN}$, et al. Unintended medication discrepancies at the time of hospital admission. Arch Intern Med 2005;165(4):424-429.

Rochelle Johnston, BSCPharm, ACPR, is with the Pharmacy Department, Horizon Health Network, Zone 1 Moncton, Moncton, New Brunswick.

Lauza Saulnier, BScPharm, ACPR, is with Research and Patient Safety Services, Horizon Health Network, Moncton, New Brunswick.

Odette N Gould, PhD, is with the Department of Psychology, Mount Allison University, Sackville, New Brunswick. She is also a Research Associate with Horizon Health Network

Address correspondence to:

Rochelle Johnston

Pharmacy Department

Horizon Health Network, Zone 1 Moncton

135 MacBeath Avenue

Moncton NB E1C $6 Z 8$

e-mail: Rochelle.Johnston@HorizonNB.ca 